\title{
Positron Annihilation spectroscopy of Basaltic Rocks from Plio-Qaternary Volcanics, Sana'a-Amran Volcanic Field, Yemen
}

\author{
K. R. Mahmoud 1,;, (D), Mohamed Th. S. Heikal2, (D) \\ ${ }^{1}$ Physics Department, Faculty of Science, Kafrelsheikh University, Kafr El-Sheikh 33511, Egypt \\ ${ }^{2}$ Geology Department, Faculty of Science, Tanta University, Tanta 31527, Egypt \\ *Corresponding authors: E-mail: kamalreyad@sci.kfs.edu.eg; Mohamed.hekal1@science.tanta.edu.eg
}

DOI: $10.5185 /$ amlett.2021.041624

We focus a new application of positron annihilation lifetime spectroscopy and Doppler broadening techniques at the annihilation sites have been applied on some basaltic rocks from inactive volcano related to Sana'a-Amrana volcanic Field (SAVF). A brief geologic set up and the main petrographic signature of this inactive volcano are given. To gain an insight into geological environment, open nanospaces in the well-characterized basaltic rocks were investigated by positron annihilation spectroscopy. The analysis of the lifetime spectra yielded two lifetime components. The olivine basalt samples contain less mono- vacancies than those found in the trachybasalt and vesicular basalt samples. The overall defect (vacancy) concentration and its variation in the samples were estimated using the mean positron lifetime $\left(\tau_{\mathrm{m}}\right)$. The Doppler broadening parameters ( $S$ and W-Parameters) were measured. A little variation of the S-parameter values has been observed for all the studied samples indicating that the valance electron contribution to annihilation is not significant.

\section{Introduction}

Yemen Volcanic Group (YVG) includes two major categories; Tertiary Volcanics and Qaternary Volcanics [1-3] ranging in age from Oligocene to Plio-Qaternary [3]. It covers some $50,000 \mathrm{~km}^{2}$. There are many occurrences of Plio-Qaternary volcanics in Sana'a and along Sana'aAmran road giving rise to much more inactive volcanoes $\left(\sim 800 \mathrm{Km}^{2}\right)$ that called Sana'a-Amran Volcanic Field (SAVF) (Fig. 1). This volcanic field is characterized by scoriaceous basalt $[\mathbf{3 , 4}]$. The present study addresses some basaltic rocks from Hemat Madam Volcano (HMV) which is a part of SAVF (Fig. 1). It covers about $1.2 \mathrm{~km}^{2}$ with altitude about $2366 \mathrm{~m}$ (a.s.1.).

Positron annihilation spectroscopy (PAS) is well known as a powerful technique for examining the microstructure of the matter and a unique spectroscopic technique for studying defects in solids [8-10]. Two PAS techniques were used: positron lifetime spectroscopy (PALS), and Doppler broadening of annihilation radiation (DBAR). Combination of used positron annihilation techniques is able to describe complex characterization of various material microstructures, i.e., positron lifetime spectroscopy determines the amount and size of vacancies in their lattice. On the other hand, the energy/momentum distribution techniques as Doppler broadening spectroscopy (DBS) describes quantity of vacancies and their clusters, their concentration, microstructural and chemical changes.
In this work, we aimed to gain a brief geologic set up, open nanospaces in natural minerals in the rocks using positron annihilation spectroscopy. Furthermore, we present results of positron annihilation study of wellcharacterized scoriacous basaltic rock samples in order to check if the nano-porosity structure of the matter observed with positronium atoms depends on the basaltic rock origin. In case of Plio-Qaternary basalt, so far the present study represents the first one with this technique, however, few workers used this technique to sandstones, carbonate rocks, opal mineral, natural minerals and rocks (e.g., see references [11-13]. They concluded that this technique is powerful to discriminate among the physical parameters and origin for both some minerals and rocks.

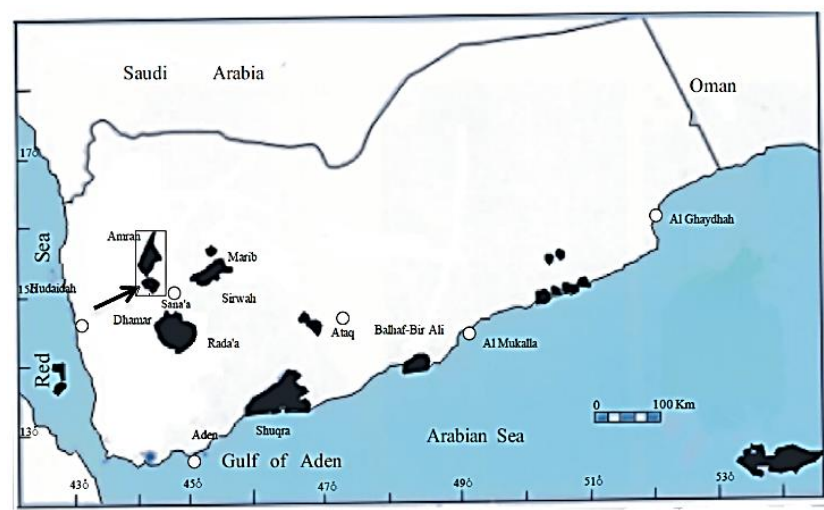

Fig. 1. Location map showing the distribution of Quaternary volcanic fields of Yemen. The study area within the box is indicated by arrow. 


\section{Advanced Materials Letters www.vbripress.com/aml}

\section{Experimental methods}

\section{Geologic set up and petrographic signature}

A brief geological setting on Hemat Madam PlioQaternary scoriaceous basalt ( $\leq 15 \mathrm{Ma},[3])$. (Fig. 1) from Sanala-Amran Volcanic Field (SAVF) is given below.

Inactive volcano $\left(1.2 \mathrm{~km}^{2}\right)$ from Sanaa-Amran volcanic field constitute a cone-hill of altitude about 340 $\mathrm{m}$, showing three phases of rock types from foothill to tophill; olivine basalt, trachy basalt and vesiculat basalt.

On the basis of petrographic signature, olivine basalt and trachybasalt have porphyritic, glassy and vesicular textures. Almost crystals are generally small (less than 1 $\mathrm{mm})$ consisting of olivine, Ca-plagioclase $\left(\mathrm{An}_{60-70)}\right.$ and augite in association with spherulites (Fig. 2(a-b)) together with subordinate ilmenite and magnetite. The groundmass is composed of cluster aggregates of plagioclase laths and minor crystals of clino-pyroxene and opaques. Pronounced macroscopic vesicles are well notified (Fig. 2(c-d)) Origin of vesicles was discussed before [5-6].
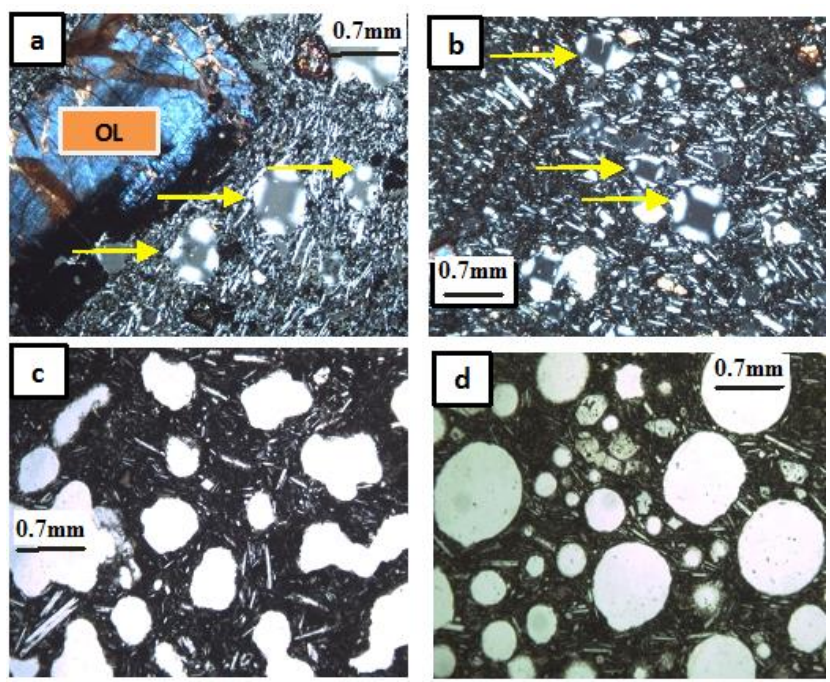

Fig. 2a-d. Photomicrographs of basalt flow in Hemat Madam Volcano, Sanaa-Amran Field volcanics. (a) Olivine basalt showing euhedral crystal of olivine (OL) embedded in flow groundmass composing of labrodorite laths and spherulites scoria (yellow arrows), sample BA-3, from the foothill of volcano. Crossed polars. (b) Trachybasalt showing flow fashion of ca-rich plagioclase laths in association with spherulites scoria (yellow arrows), sample $\mathrm{BH}-3$ from the middle part of volcano. Crossed polars. (c-d) Highly vesicular basalt showing irregular to ovoidal-shaped of vesicles, The vesicles are filled with glassy materials, embedded in more or less flow groundmass consisting of fine laths of Ca-rich plagioclase, samples KH-4 \& KH-1 from the tophill of volcano. Plane Polarized Light

\section{Positron annihilation measurements}

Positron annihilation lifetime (PAL) measurements on the present samples of basaltic rocks were done using the fastfast coincidence spectrometer [15-16]. This spectrometer has a resolution of $\sim 350 \mathrm{ps}$ measured using a ${ }^{60} \mathrm{Co}$ source for the PAL measurements. About $15 \mu \mathrm{Ci}$ activity of $22 \mathrm{Na}$ isotope was deposited then dried on $3 * 3 \mathrm{~cm}$ of thin layer of Kapton foils ( $7.6 \mu \mathrm{m}$ thick), covered with similar pice of foil and were afterward glued with epoxy glue, placed between two identical volcanic samples. Each sample was measured at leat 2-3 times differed by a total number of elementary annihilation events in the range of 1- 2 million counts. The PAL spectra were fitted and analyzed by the LT (ver. 9) computer program of Kansy [11], with a suitable correction for the positrons annihilated in the Kapton. Every PAL spectrum was treated because of the little changes in the number of final channels, background of annihilation and time shift of the spectrum. The best results were selected at the basis of FIT, determined as statistically weighted least-squares deviation between experimental points and theoretical curve [17]. The obtained results with FIT values ranged from 0.965 up to $\sim 1.1$ to 1.2 are only considered as optimal ones. This FIT values and determined PAL characteristics were controlled in dependence on background of annihilation and time shift of PAL spectrum. After source correction, each lifetime spectrum was resolved into two lifetime components, $\tau_{1}$ and $\tau_{2}$ with relative intensities $I_{1}$ and $I_{2}$ respectively. They refer to the relative number of annihilated positrons with those lifetimes to the different annihilation processes.

\section{Positron annihilation doppler broadening measurements}

The spectrometer used in this study is a p-type high-purity germanium detector (Ortec, GEM series) with $1.6 \mathrm{keV}$ energy resolution (FWHM) for $1.33 \mathrm{MeV}$ gamma line of ${ }^{60} \mathrm{Co}$ and $25 \%$ relative efficiency. A 919 multichannel analyzer (MCA) from Ortic was used to acquire the amplified signals from Ortec 570 amplifier. The energy calibration for the spectrometer was $\sim 68 \mathrm{eV} /$ channel obtained using ${ }^{133} \mathrm{Ba}$ source. A positron source with an activity of $0.5 \mu \mathrm{Ci}^{22} \mathrm{Na}$ was used, which prepared using a droplet of ${ }^{22} \mathrm{NaCl}$ solution was dried onto two identical Kapton foils $(7.5 \mu \mathrm{m}$ thick). Two disk samples were arranged with the ${ }^{22} \mathrm{Na}$ source in a $4 \pi$ configuration. The Doppler broadening measurements were done in air at room temperature for accumulate more than three million counts for each spectrum. The obtained data were analyzed using SP ver. 1.0 program. The centroid channel with maximum counts of the spectrum peak at $511 \mathrm{keV}$ was carefully determined as the base for $\mathrm{S}-$ and $\mathrm{W}-$ parameters calculations.

\section{Results and discussion}

The studied samples of basalts collected from HMV is a part Sana'a-Amran Volcanic Field (SAVF) represent a natural material of multi-components, not a single compound, comprising specific chemical composition for each component. The main mineral phases constitute the present rock samples are; olivine $[\mathrm{Mg}, \mathrm{Fe}]_{2}\left[\mathrm{SiO}_{4}\right]$, clinopyroxene, augite [ $\mathrm{Ca}, \mathrm{Na}, \mathrm{Mg}, \mathrm{Fe}^{+2}, \mathrm{Mn}, \mathrm{Fe}^{+3}, \mathrm{Al}$, $\mathrm{Ti}]_{2}\left[(\mathrm{Si}, \mathrm{Al})_{2} \mathrm{O}_{6}\right]$, Ca-rich plagioclase $\left[\mathrm{Ca}, \mathrm{Na}, \mathrm{Al}_{2} \mathrm{SiO}_{3}\right.$ $\left.\mathrm{O}_{8}\right]$, Magnetite $\left[\mathrm{Fe}_{3} \mathrm{O}_{4}\right]$ and ilmenite $\left[\mathrm{FeO} . \mathrm{TiO}_{2}\right]$ in association with glass materials. The foothills volcano has enrichment with olivine basalt (5 phases; olivine, augite, Ca-plagioclase, magnetite and imenite), whereas, the 


\section{Advanced Materials Letters www.vbripress.com/aml}

middle part of volcano is mainly composed of trachybasalt ( 3 phases; augite, Ca-plagioclase and magnetite), but the top hill of volcano comprises Ca-plagioclase and volcanic glass (in major) and very minor components of magnetite, ilmenite \pm olivine and augite. These various chemical components among three phases of volcanic eruption, exactly reflect the different physical and chemical behavior from the bottom (foothill) to the top hill of volcano, taking into consideration that the basalt must reach temperature above $1000^{\circ} \mathrm{C}$ before melting will begin. On the other hand, the vesicular basalt represents the final stage of volcanic eruption; it is mostly used as an excellent building stone in many habitats of Yemen and Saudi Arabia, due to its very high durability.

Positron lifetime spectra obtained were analyzed in terms of two components of positron lifetimes $\tau_{1}$ and $\tau_{2}$, and their corresponding intensities $I_{1}$ and $I_{2}$ for the present study samples. Here $\tau_{1}$ and $\tau_{2}$ and $I_{2}$ have been assigned as positron lifetime in the bulk or mono- vacancies, the positron lifetime in sub-nanoscale pores, and the intensity of positrons in the sub-nanoscale pores, respectively. The positron lifetimes $\tau_{1}$ and their relative intensities $I_{1}$ are plotted together with the data of olivine basalt (BA3 \& BA7), trachybasalt (BH3 \& BH9) and highly vesicular basalt rock (KH1, KH4 \& KH7) samples in Fig. 3. The results in Fig. 3 ranged from 264 to 309ps for all the studied samples, whereas $I_{1}$ ranged from 93 to $97.8 \%$ for all the studied samples. Some Variations of $\tau_{1}$ were shown for the all studied samples may be due to the different composition in each sample, which is difficult to determine quantitatively. The data showed that the value of $\tau_{1}$ and its intensity $I_{1}$ for the olivine basalt samples (BA3 \& BA7 from the foothill of volcano) are consistently smaller than trachybasalt specimens (BH3 \& BH9 from the middle part of volcano) and the highly vesicular basalt (samples KH1 \& KH4) indicating that olivine basalt samples contain less mono- vacancies than the trachybasalt and vesicular basalt samples. However, we have to get a great caution when interpreting short lifetimes [18].

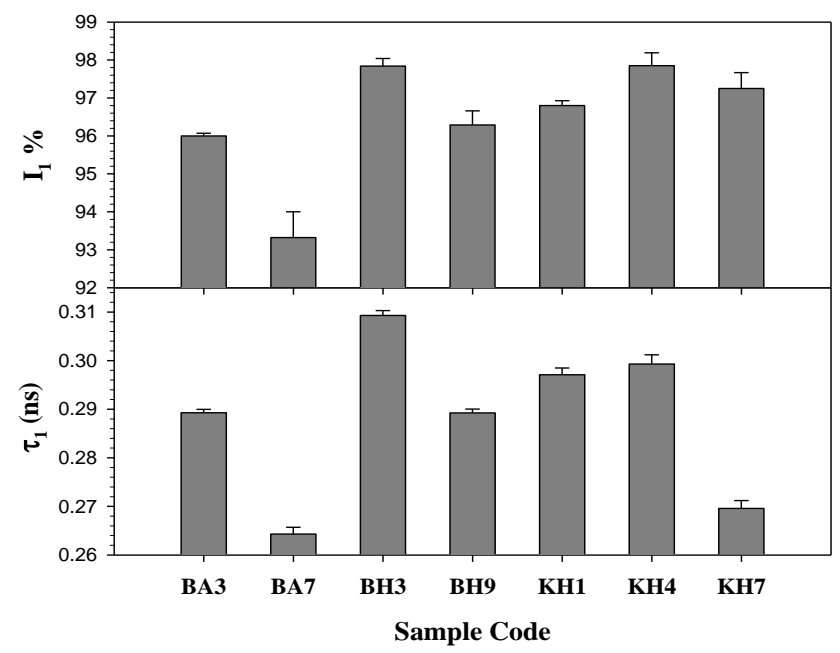

Fig. 3. The measured values of the lifetime component $\tau_{1}$ and corresponding intensity $\mathrm{I}_{1}$ for the collected volcanic samples.
The positron lifetimes $\tau_{2}$ and their relative intensities $I_{2}$ are also plotted together with the data of olivine basalt, trachybasalt and highly vesicular basalt samples (Fig. 4). The results indicated that the lifetime $\tau_{2}$ ranges from 0.6 $\mathrm{ns}$ to $1.32 \mathrm{~ns}$, indicating the presence of sub-nanoscale pores in the studies samples. The lifetime $\tau_{2}$ and its relative intensities $I_{2}$ obtained for the olivine basalt samples (BA3 \& BA7 from the foothill of volcano) are consistently smaller than trachybasalt specimens from the middle part of volcano and the highly vesicular basalt (samples KH1, KH4 \&KH7) indicating that the olivine basalt samples contain less nano pores than in trachybasalt and the highly vesicular basalt specimens. The mean reason for this may be due to the compact structure of the vesicular basalt samples. This compaction effect could reduce the size of sub-nanoscale pores during its formation process at underground. It is clear from the results in Fig. 4 that, the samples BH3 and KH1 have the highest values of $\tau_{2}(1.016$ and $1.32 \mathrm{~ns}$ respectively) with nearly low values $I_{2}(<3 \%)$ probably due to positron annihilation at the surface and the imperfect regions of the materials. This result is consistent with that measured for the volcanic glasses $\tau_{2}(\sim 1.5 \mathrm{~ns})$ by SATO et. al., [13].

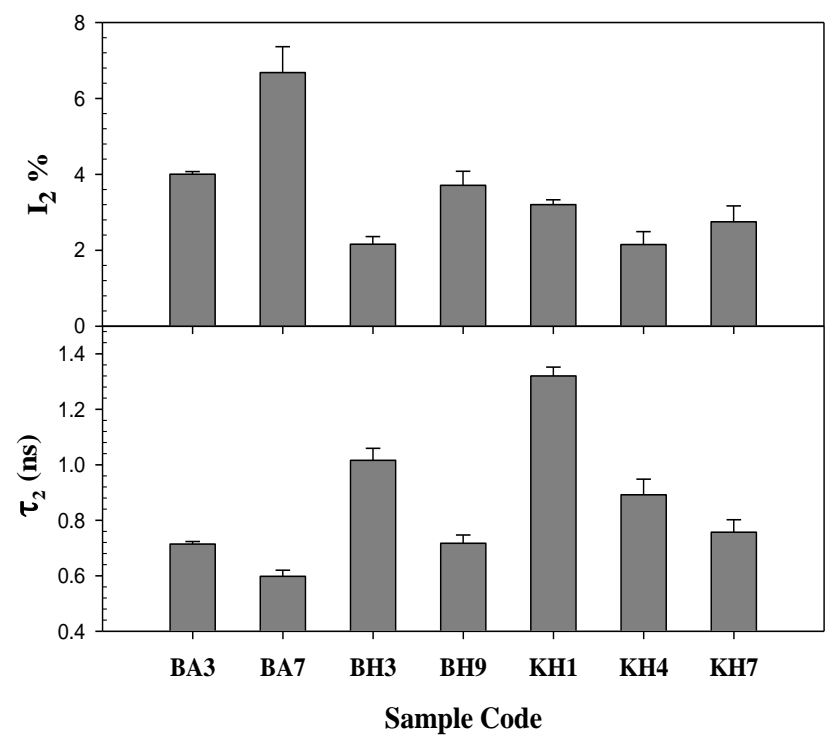

Fig. 4. The measured values of the lifetime component $\tau_{2}$ and corresponding intensity $\mathrm{I}_{2}$ for the collected volcanic samples.

To evaluate the overall defect concentration (vacancy concentration) in the samples, the mean positron lifetime $\left(\tau_{\mathrm{m}}\right)$ was calculated using the relation [19]:

$$
\tau_{m}=\frac{\tau_{1} I_{1}+\tau_{2} I_{2}}{I_{1}+I_{2}}
$$

Fig. 5 shows the variation of the mean positron lifetime $\left(\tau_{\mathrm{m}}\right)$ for all the investigated samples. It clears from Fig. 5 that there is variation in $\tau_{\mathrm{m}}$ can be noticed for all collected samples and it was found that $\tau_{\mathrm{m}}$ values are quite high in comparable to the calculated bulk lifetime $\left(\tau_{\mathrm{b}}\right)$ in the samples $(226 \pm 29 \mathrm{ps})$, which assert the presence of large vacancies in the samples. 


\section{Advanced Materials Letters www.vbripress.com/aml}

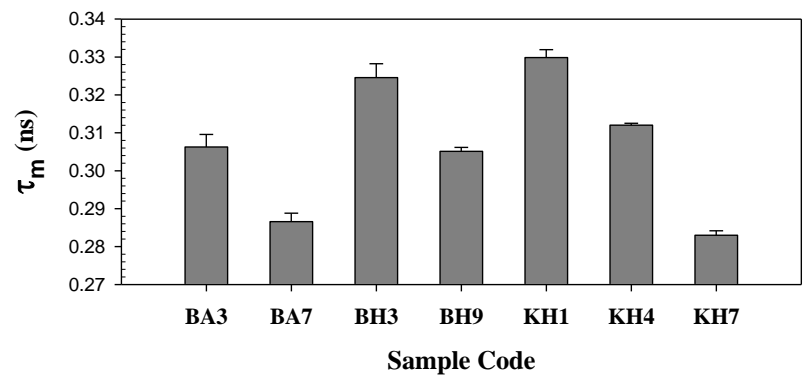

Fig. 5. The variation of the calculated values of the mean positron lifetime $\left(\tau_{\mathrm{m}}\right)$ for the collected volcanic samples.

Since the DB annihilation gamma ray spectrum is the total number of the contributions of annihilations with different electron states at the annihilation site. Therefore, annihilations with delocalized and weakly bound valence electrons contribute to the low-momentum part of the momentum distribution, whereas tightly bound core electrons contribute to the high momentum part. Doppler broadening (DB) of annihilation line technique is used to detect the concentrations of defects such as vacancies and their accumulations, by calculating the two important parameters, called $\mathrm{S}$ and $\mathrm{W}$-parameter, from analysis of the shape of annihilation line. The S-parameter is defined by Mackenzie et. al., [20] as the ratio of the area under the semi symmetric fixed central region of the annihilation line to the area under the whole annihilation line. As the electrons in the interstitial regions of a perfect lattice have a little higher momentum in comparison with low momentum electrons which are present in the open volume defects, then the S-parameter is sensitive to the average density of the open volume defects in the medium. The $\mathrm{W}$-parameter was defined as the ratio of the area under the constant wing region of the annihilation line to the area under the whole annihilation line [21]. Since the high potential barriers experienced by a positron in the regions near to nuclei, annihilation with deeply bound core electrons is very implausible as compared to annihilation with outer electrons, thus the high momentum part of the annihilation line belong to the positron annihilation with core electrons.

With respect of Fig. 6 that reveals the variation of Sand $\mathrm{W}$-parameters of the different samples of olivine basalt (BA3 \& BA7), trachybasalt (BH3 \& BH9) and highly vesicular basalt rock (KH1, KH4 \& KH7) samples. The results in Fig.6 indicated that a little variation of the S-parameter values has been observed for all the studied samples indicating that the valance electron contribution to annihilation is not significant. On the other hand, the values of $\mathrm{W}$-parameters are higher for trachybasalt (BH3 \& BH9) and vesicular basalt (KH1, KH4 \& KH7) samples than that found in olivine basalt (BA3 \& BA7) samples. A steep increase of the $\mathrm{W}$-parameter values has been observed for olivine basalt (BA3 \& BA7) samples. This increase may be due to the presence of olivine and iliminite as a major constituents in the foothill samples. In addition, these samples have small values of $\mathrm{W}$-parameter in comparison to the other samples from other location as shown in Fig. 6. This indicates that the positrons annihilated with the valance electrons more than that annihilated with core electrons for these samples.

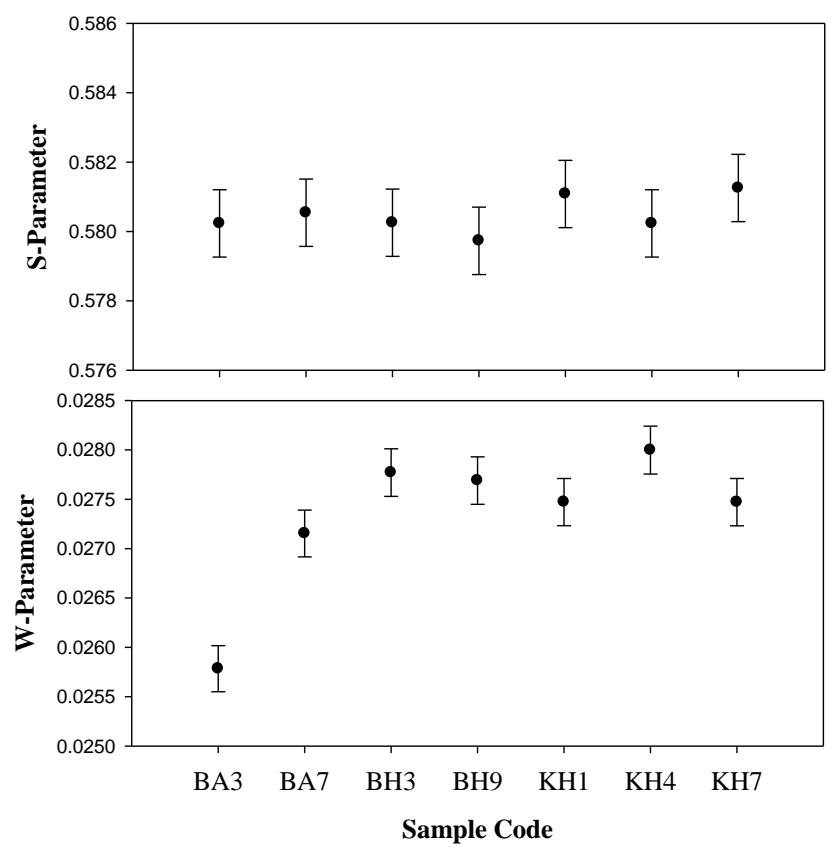

Fig. 6. The measured values of $\mathrm{S}-$ and $\mathrm{W}$-parameters for the different samples of olivine basalt (BA3 \& BA7), trachybasalt (BH3 \& BH9) and highly vesicular basalt rock (KH1, KH4 \& KH7) samples.

\section{Conclusions}

Hemat Madam Plio-Qaternary volcano represents a tiny part of (SAVF). It comprises three main rock types from the foothill to top hill; olivine basalt, trachybasalt and vesicular basalt reflecting the typical scoriaceous basalt volcano. The studied samples represent a natural material of multi-components with slight different mineralogical and chemical compositions. We have presented results of positron annihilation lifetime spectroscopy and Doppler broadening of annihilation radiation to the wellcharacterized scoriacous basaltic rock samples. In the lifetime measurements we have observed that the spectra from the rocks can be fitted with the assumption of two discrete lifetimes. The obtained results showed that olivine basalt samples contain less mono-vacancies than the trachybasalt and vesicular basalt samples. It was found also that olivine basalt samples contains less nano pores than in trachybasalt and the highly vesicular basalt specimens which may be due to the compact structure of the vesicular basalt samples. This compaction effect could reduce the size of sub-nanoscale pores during its formation process at underground.

The Doppler broadening measurements showed a little variation of S-parameter for all studied samples indicating that the valance electron contribution to annihilation is not significant. The olivine basalt samples have small values of $\mathrm{W}$-parameter in comparison to the other samples from other location indicated that the positrons annihilated with the valance electrons are more 


\section{Advanced Materials Letters www.vbripress.com/aml}

than that annihilated with core electrons. Recently, the vesicular basalt in Isbil volcano, SE Yemen, which is identical to the same rock types in the present work, it is successfully used as natural catalysis in some chemical reactions [22] and semiconductor materials [23].

\section{Acknowledgment}

We strongly appreciate Ms. Fatma A. Farrag, Manager of Translation and Editing Services, Atomic Energy Authority, Egypt for performing the language editing of this paper.

\section{Keywords}

Positron annihilation spectroscopy, doppler broadening, free volume, plio-qaternary basaltic rock, Yemen.

\section{Received: 20 April 2020}

Revised: 31 December 2020

Accepted: 10 January 2021

\section{References}

1. White, R.S.; Spence, G.D.; Fowler, S.R.; McKenzie, D.P.; Westbrook, G.K.; Bowen, A.N.; Nature, 1989, 330, 439.

2. White, R.S.; McKenzie, D.P.; J. Geophysics Res., 1989, 96, B6, 7685.

3. Baker, J.A.; Menzies, M.A.; Thirlwall, M.F.; Macpherson, C.G.; J. Petrology, 1997, 38, 1359.

4. Luigi, B.; Gianluca, B.; Claudio, N.; Franca, S. J.; Petrology, 2009, 50, 1377.

5. Mattash, M.A.; Pinarelli, L.; Vaselli, O.; Minissale, A.; Al-Kadasi, M.; Shawki, M.N.; Tassi, F.; IJG., 2013, 4, 1459.

6. Heikal, M.Th.S.; Lebda, E.M.; Orihashi, Y.; Habtoor, A.; Arab. J. Geosciences, 2014, 7, 69 .

7. Heikal, M Th.S.; Lebda E. M.; Khalf, E.; Arab. J. Geosciences, 2019. 12, 723 .

8. Wu, Y.C.; Zhang, R.; Chen, H.; Li, Y.; Zhang, J.; Zhu, D.M.; Jean, Y.C.; Radiat. Phys. Chem., 2003, 68, 599.

9. Wu, Y.C.; Chen, Y.Q.; Wang, B.; Wang, S.J.; Jean, Y.C.; Suzuki, R.; Ohdaira, T.; Appl. Surf. Sci., 2006, 252, 3274.

10. Chen, Y.Q.; Wu, Y.C.; Wang, Z.; Wang, S.J.; Radiat. Phys. Chem., 2007, 76, 308.

11. Urban-Klaehn, J.M.; Quarles, C.A.; J. Appl. Phys., 1999, 86, 355.

12. Chojcan, J.; Sachanbiński, M.; Idczak, R.; Konieczny, R.; Nukleonika, 2013, 58, 225.

13. Sato, K.; Fujimoto, K.; Nakata, M.; Hatta, T.; Shikazono, N.; Olomouc, Czech Republic, EU, 2010, 10, 12.

14. Mahmoud, K.R.; Al-Sigeny, S.; Sharshar, T.; El-Hamshary, H. Radiat. Phys. Chem. 2006, 75, 590-595.

15. Assem, E.E.; Mahmoud, K.R.; Sharshar, T.; Siligardi, C.; J. Phys. D: Appl. Phys., 2006, 39, 734.

16. Kansy, J.; Nucl. Instrum. Methods A, 1996, 374, 235.

17. Shpotyuk, O.; Filipecki, J.; Kozdras, A.; Hyla, M. In Contributions to Non-Crystalline Semiconductor Physics and to Optoelectronics. Chisinau, Moldova, 2003, 140.

18. Wästlund, C.; Eldrup, M.; Maurer, F.H.J.; Nucl. Instr. Method B, 1998, 143, 575.

19. Mishra, A.K.; Das, D.; Materials Science and Engineering B, 2010, 171,5 .

20. Mackenzie, I.K.; Eady, J.A.; Gingerich, R.R.; Phys. Lett., 1970, 33A, 279.

21. Abdel-Rahman, M.; Eissa, M.F.; Kamel, N.A.; Egypt. J. Solids, $\mathbf{2 0 0 9}, 32,23$

22. Said, A.; Heikal, MTh.S.; Guda, M.; J. Chin Chem Soc., 2019, 66, 725.

23. Eraky, M.R.; Heikal, M.Th.S.; Adv. Mater. Lett., 2020, 11, 20021477. 